\title{
CONTRIBUIÇÕES DO INVESTIMENTO ANJO PARA O DESENVOLVIMENTO DE STARTUPS NA REGIÃO METROPOLITANA DE PORTO ALEGRE
}

\author{
ANGEL INVESTOR'S CONTRIBUTION TO STARTUP DEVELOPMENT \\ IN THE METROPOLITAN REGION OF PORTO ALEGRE
}

\author{
Tatiana Spaniol Mengue \\ Bacharela em Administração pela \\ Universidade Feevale (Novo Hamburgo/Brasil).
}

\section{Serje Schmidt}

Doutor em Economía de L'Empresa pela University of the Balearic Islands (Espanha) e em Administração de Empresas pela Universidade do Vale do Rio dos Sinos (São Leopoldo/Brasil).

Professor na Universidade Feevale (Novo Hamburgo/Brasil).

\author{
Maria Cristina Bohnenberger \\ Doutora em Economía de L'Empresa pela \\ University of the Balearic Islands (Espanha). \\ Professora na Universidade Feevale (Novo Hamburgo/Brasil).
}




\section{RESUMO}

O presente estudo aborda o papel dos investidores-anjo como apoiadores de startups e fomentadores do empreendedorismo. O objetivo geral consiste em verificar a influência do Investimento Anjo no desenvolvimento de startups na região metropolitana de Porto Alegre. Foi realizada uma pesquisa descritiva com caráter exploratório, com abordagem qualitativa, por meio de entrevistas com quatro investidores e sete empreendedores, selecionados por meio da técnica snowball. As entrevistas foram realizadas na região metropolitana de Porto Alegre. A partir dos resultados, pode-se observar que os investidores contribuem com capital de risco, conhecimento e experiência, suporte à rede de contatos, acesso a pessoas e recursos estratégicos, além de outros auxílios mencionados, como espaço físico para trabalho e também feedbacks sobre o projeto. Assim percebe-se que o Investimento Anjo se torna uma forma de fomentar o empreendedorismo, por intermédio de contribuições diferenciadas que auxiliam as startups a se desenvolver.

Palavras-chave: Inovação. Startup. Investidor Anjo. Capital de risco. Empreendedorismo.

\section{ABSTRACT}

This study approaches the role of Angel Investors as startups supporters and entrepreneurship. The overall aim consists of verifying the influence of Angel Investment to the development of startups in the metropolitan area of Porto Alegre. A descriptive, exploratory, qualitative survey was performed, interviewing four investors and seven entrepreneurs, selected by the snowball method. The interviews were performed in the metropolitan area of Porto Alegre. From the results, it was possible to observe that investors contribute with venture capital, knowledge and experience, networking support, facilitating access to strategic people and resources, as well as other mentioned assistance, as physical space to work and feedbacks about the project. Thus, it is notices that the angel investment becomes a way to promote entrepreneurship, by distinctive contributions that help on startups development.

Keywords: Innovation. Startup. Angel Investor. Venture capital. Entrepreneurship. 


\section{INTRODUÇÃO}

O empreendedorismo é abordado como fonte geradora de inovação, sendo Schumpeter (1934) o primeiro autor a trazer essa concepção. O modelo de empresa Startup materializa esse conceito, por meio da criação e implementação de produtos ou serviços inovadores em que o processo de inovação se diferencia das empresas tradicionais (BORGES, 2016).

Estas empresas têm sido consideradas como recursos para o desenvolvimento econômico e tecnológico, trazendo o conceito de novos produtos e serviços de alta escalabilidade com produção acelerada. Essas organizações foram surgindo ao longo dos últimos anos e trouxeram alterações significativas no estilo de vida das pessoas. Esse reflexo tem sido importante especialmente em mercados cuja demanda é estimulada pela busca de conforto e soluções de problemas cotidianos (BENVENUTTI, 2016).

As startups necessitam de aporte de diversos tipos de recursos para iniciarem suas atividades, principalmente financeiros. Comumente, a origem dos recursos iniciais advém do empreendedor e seus sócios, cuja restrição orçamentária impede a continuidade do projeto. A busca por financiamento em órgãos públicos ou instituições financeiras também é limitada pela falta de garantias como contrapartida do recurso recebido (MINEIRO et al., 2016).

Os investidores-anjo (IA) surgiram com a intenção de atuar nessa lacuna de obtenção de recursos pelas organizações iniciantes, constituindo-se em importantes apoiadores de projetos nascentes. Além do investimento financeiro, esses investidores costumam proporcionar outros tipos de recursos ao empreendedor, como capital intelectual e social, colaborando com suas redes de contatos e conhecimentos em gestão. Dessa forma, os investidores tornaram-se grandes fomentadores do empreendedorismo, contribuindo para o desenvolvimento da sociedade, gerando empregos e inovações (SPINA, 2015).

Entretanto, a relevância desse assunto, tanto pela atual situação econômica do Brasil quanto pelo incremento na oferta por essa modalidade de financiamento, contrasta com a carência de evidências empíricas que deem conta de confirmar (ou não) os diversos tipos de contribuição proporcionados pelos IAs. Dessa forma, o problema que será abordado neste estudo é: qual o papel dos investidores-anjo para o desenvolvimento das startups? Este trabalho tem por objetivo verificar a influência do Investimento Anjo no desenvolvimento de startups. A metodologia utilizada neste trabalho consistiu em uma pesquisa descritiva com caráter exploratório, utilizando entrevistas semiestruturadas com os empreendedores e investidores.

O estudo está estruturado em seis seções. Nas duas seções seguintes após esta introdução, serão abordados o Investimento Anjo e suas potenciais contribuições aos empreendedores, que subsidiaram 
os instrumentos de coleta de dados. A seção de método descreve o delineamento epistemológico da pesquisa, os roteiros para coleta de dados e como os dados foram coletados. A seção 5 traz a análise dos resultados, organizada de acordo com as categorias tecidas na seção de fundamentação teórica. 0 estudo finaliza trazendo as considerações finais e as implicações para a teoria e para o ambiente empírico.

\section{INVESTIMENTO ANJO}

Quando empresas nascentes de alta tecnologia necessitam de financiamento externo, dificilmente obtém recursos de bancos comerciais. O risco do empréstimo via mercado é muito alto, e elas ainda não geram receitas suficientes para garantir o pagamento. Assim, pela escassez de recursos, incentivos privados para essas empresas advêm de investidores de risco e se tornam extremamente importantes para empreendedores que possuem dificuldades para financiar seus projetos (FERRARY; GRANOVETTER, 2009).

$O$ investimento privado pode ocorrer formal ou informalmente, concentrando-se em três tipos: Investimento Anjo, Capital de Risco e Fundos de Private Equity (PAVANI, 2003). A origem do termo "investidor-anjo" advém de investidores privados que financiavam a produção de peças na Broadway (EUA), apoiando a sua execução, assumindo os riscos e participando nos eventuais retornos financeiros (SPINA, 2015). O investidor anjo é "um indivíduo que investe em empresas no seu primeiro estágio de desenvolvimento (seed), usualmente na fase de concepção do negócio ou no desenvolvimento do produto" (BALDASSI; CRISPIM, 2009, p. 6).

Capital de Risco é aportado por empresas juridicamente constituídas com a finalidade de realizar investimentos em startups, em estágio inicial ou em desenvolvimento. Elas buscam "[...] operações em negócios de menor porte e modelos de negócios não testados, com alto potencial de retorno, mas com altos riscos associados" (PAVANI, 2003, p. 34).

Já o Private Equity $(\mathrm{PE})$ refere-se a aportes financeiros realizados em empresas em estágios mais avançados, onde as organizações já apresentam lucro, mas com envolvimento semelhante do gestor (CARVALHO; RIBEIRO; FURTADO, 2006).

A fim de minimizar a ameaça de perda de capital os IAs agem eventualmente em grupos. A atuação individual é mais arriscada, há maiores dificuldades para encontrar oportunidades de investimento e falhas de comunicação entre empreendedor e investidor são mais prováveis. A atuação em grupos pode se tornar mais vantajosa também pelo compartilhamento de técnicas, habilidades e experiências de investimento (MINEIRO et al., 2016). Grupos de investidores, por serem mais fáceis de encontrar e terem uma estrutura mais organizada, facilitam o acesso para o empreendedor. Gávea Angels e Anjos do Brasil são exemplos de grupos de investidores-anjo brasileiros. 


\subsection{MOTIVAÇÕES DOS INVESTIDORES-ANJO}

Desde o seu surgimento, os IAs atuam em mercados de alto risco, onde não há garantias de sucesso, mas podendo ter retorno alto sobre o investimento realizado. Os retornos esperados consistem na valorização da empresa à medida que essa se desenvolve, cresce e apresenta resultados financeiros sólidos. Assim, ao invés do retorno financeiro imediato, os IAs pretendem ganhar com o reconhecimento da empresa no longo prazo, podendo resultar na abertura de capital ou na sua venda para grandes corporações (BARROS; TODA; RAMOS, 2016).

Outras motivações também podem ser observadas nas características dos projetos envolvidos. Propostas que abordam questões sociais, humanitárias, de melhoria da qualidade de vida, com impacto social ou ambiental relevante, ou até questões mais restritas ao benefício individual do IA, como por exemplo um desafio intelectual, atualização tecnológica ou possibilidade de formação de redes de contato, também possuem um apelo à dedicação de recursos por parte desses investidores (BOTELHO; DIDIER; RODRIGUEZ, 2006).

A assimilação do investidor com o projeto e com as pessoas com quem irá lidar durante o processo torna-se mais um incentivo para o investimento. Nessa relação, credibilidade entre as partes é um elemento essencial para que a relação seja harmoniosa (HORBUCZ, 2015). Mason e Stark (2004), por exemplo, enfatizam a necessidade de haver empatia entre investidor e empreendedor. Para a seleção de um projeto, o investidor pode levar em consideração a motivação, a perseverança e a persistência do empreendedor (SPINA, 2015). Fatores estruturais do projeto também podem desenvolver maior interesse do investidor. Entre esses, Bessant e Tidd (2011) mencionam: equipe de gestão bastante ampla e experiente, patentes registradas e alianças industriais.

Essas motivações levam a um envolvimento maior com a empresa nascente, eventualmente a uma participação societária superior do que investidores que aportam recursos apenas quando a empresa apresenta lucros. Nas fases de expansão e consolidação do negócio, onde a organização já apresenta lucros consolidados, o investimento pode se originar de outras modalidades. Então, quando o investidor sai do negócio, os resultados do projeto podem ter sido satisfatórios (ou não) do ponto de vista financeiro, mas o aprendizado durante todo o processo terá gerado ganho pessoal, tanto para o investidor como para o empreendedor (SPINA, 2015). 


\subsection{PROCESSO DE RELACIONAMENTO ENTRE INVESTIDOR E EMPREENDEDOR}

A construção do relacionamento se inicia quando empreendedor e investidor encontram a sua contraparte. É importante que ambos avaliem as possibilidades a fim de se unirem a parceiros que realmente possam agregar ao negócio. Inicialmente deve haver um alinhamento de objetivos, onde o empreendedor e investidor devem apresentar seus propósitos, para não haver conflito de interesses (SPINA, 2015). Esse alinhamento de objetivos pode ser bastante desafiador, pois integrar as expectativas entre os diferentes atores nesse processo não é simples. Mesmo que inicialmente a parceria pareça ser bastante vantajosa, quando os benefícios esperados não são rapidamente alcançados, os parceiros podem perder o interesse, resultando em uma inércia colaborativa e um lento progresso (GRAY, 2008).

$\mathrm{O}$ acordo acaba sendo o resultado do alinhamento de objetivos traçados anteriormente, devendo ser justo para ambos, para que as partes se sintam satisfeitas com a adesão do acordo. 0 estabelecimento de indicadores-chave de desempenho pode auxiliar no alinhamento de expectativas mútuas. Índices de faturamento, lucro líquido e número de clientes, determinando metas a serem atingidas, poderão ajudar a encontrar uma forma de equilibrar os interesses de todos os envolvidos e instaurar uma relação mais harmoniosa. Com objetivos transparentes, deve-se ter também uma previsão de término dessa relação, pois em alguns momentos o auxílio do IA não será mais suficiente para o que a empresa necessita, o empreendedor parte para outras fases que irão demandar outros tipos de investimento (CARIS, 2006).

\subsection{CONFIANÇA}

É importante que na relação entre investidor e empreendedor haja os mais altos padrões de ética, de transparência e de honestidade mútua, pois um deslize de qualquer parte pode danificar a sua imagem que ficará marcada por muito tempo (SPINA, 2015). No contexto organizacional, empresas com melhor reputação tendem a sinalizar ao mercado mais confiança, consequentemente atraindo parceiros e obtendo recursos mais facilmente (BARNEY; HANSEN, 1994).

Sobre relações interorganizacionais, duas definições de confiança são mais encontradas na literatura: previsibilidade em relação ao comportamento da outra parte e expectativa em relação à sua boa vontade. Confiança envolve um ator que: a) pode ser confiado para cumprir obrigações; b) se comportará de maneira previsível; c) negociará de maneira justa, não se corrompendo a oportunismos (ZAHEER; MCEVILY; PERRONE, 1998).

A confiança, juntamente com o contrato, faz parte dos mecanismos de governança para relações entre organizações. A partir da relação de confiança estabelecida, parte-se para a discussão do contrato. A confiança precede o contrato, mas não o elimina. Em casos em que existe a confiança, o contrato é 
utilizado para formalizar o acordo sem maiores preocupações em relação a salvaguardas. No entanto, quando não há a confiança, o contrato é utilizado como forma de evitar oportunismos, sendo incluídas cláusulas mais restritivas (WOOLTHUIS; HILLEBRAND; NOOTEBOOM, 2005).

Embora as cláusulas contratuais possam representar garantias de que o acordo será cumprido, em alguns contextos a inclusão de muitos termos e condições em um contrato pode ser visto como sinal de que a confiança está ausente. Essa questão pode gerar desconforto entre as partes envolvidas, iniciando uma relação em que há desconfiança (DACIN; REID; RING, 2008).

O não cumprimento do acordo nem sempre está associado a oportunismo. Em muitos casos a incapacidade de prever possíveis lacunas ou até mesmo a falta de registros podem impedir o cumprimento das combinações. A relação de confiança que se estabelece torna o contrato menos relevante, havendo uma tendência maior em compartilhar informações sigilosas, subjacentes à formalidade dos contratos. Isso permite às partes trocar informações mais sensiveis (DOZ; HAMELL, 2000; RING; VAN DE VEN, 1992).

Nooteboom (2000) sugere que contratos são benéficos no sentido de evitar oportunismos e podem ser utilizados como um registro-base para a coordenação técnica, prevenindo mal-entendidos e selando a intenção de colaboração entre as partes. No entanto, há dificuldade em prever contingências futuras e os custos podem ser elevados. Ainda, o contrato pode limitar a utilização de oportunidades que poderiam beneficiar o empreendimento.

Nesse sentido, para o bom desenvolvimento do negócio, é importante o estabelecimento de regras para a relação. Essas regras podem envolver a definição de rotinas de envio de informes quanto à situação do empreendimento, solicitação de auxílio ao investidor, tempo de resposta, se o IA terá participação nas decisões e recebimento de relatórios periódicos (SPINA, 2015).

\section{CONTRIBUIÇÃO DOS IAS ÀS EMPRESAS}

Com interesse semelhante ao do empreendedor no desenvolvimento das startups, é possivel perceber que os IAs se tornam importantes fomentadores do empreendedorismo (SPINA, 2015). Eles contribuem e se dedicam ao empreendimento em troca de participação societária, podendo atuar informalmente como consultores, auxiliando organizações que têm dificuldade para conseguir o capital financeiro inicial, além de se disponibilizarem a ajudar no gerenciamento e auxiliar na facilitação para aquisição de recursos e parceiros (HARRISON; BOTELHO; MASON, 2016). Assim, os IAs podem contribuir não somente com recursos financeiros, mas também com a gestão do negócio, ajudando na organização dos processos internos e networking, promovendo parcerias estratégicas (CALVOSA; FREITAS, 2008). Essa contribuição está detalhada a seguir. 


\subsection{CAPITAL DE RISCO}

A principal contribuição dos IAs para as empresas iniciantes envolve o capital de risco, também chamado de Venture Capital. Os investidores, assim como os empreendedores, arriscam-se com o desempenho da empresa, por isso a destinação dos recursos deve ser bem analisada. Para ocorrer o direcionamento desse aporte financeiro, há requisitos a serem analisados, como o potencial de crescimento e a elevada possibilidade de retorno com o intuito de justificar os custos, a baixa liquidez e os riscos associados (CARVALHO; RIBEIRO; FURTADO, 2006).

No Brasil, o mercado de Venture Capitalpode ser considerado recente, embora esteja muito próximo da maioria dos países desenvolvidos. A experiência internacional mostra que essa é uma forma de o setor privado participar do financiamento de projetos que podem fomentar o desenvolvimento tecnológico, além de aproximar instituições (CGEE, 2003). No Vale do Silício, por exemplo, os investidores de risco são fundamentais, uma vez que os recursos financeiros investidos nos projetos movimentam todo o cluster de inovação (FERRARY; GRANOVETTER, 2009). Entretanto, pelo fato de o envolvimento dos investidores nas rotinas das empresas nem sempre ser bem visto por parte dos empreendedores, o capital financeiro acaba se tornando o maior acréscimo do investidor para a empresa (BARROS; TODA; RAMOS, 2016).

\subsection{CAPITAL INTELECTUAL}

Capital Intelectual é a soma do conhecimento de todos em uma empresa, o que Ihe proporciona vantagem competitiva (STEWART, 1998). À medida que startups progridem em seu ciclo de vida, as aptidões gerenciais se tornam mais importantes do que as habilidades empresariais (JUDICE; BAÊTA, 2005). O conhecimento dos IAs em gestão, resultado de seu histórico na participação em empresas bemsucedidas, torna-se um importante aliado na construção de estratégias de competitividade (SPINA, 2015).

O auxílio do IA pode ser especialmente benéfico nos casos em que haja resistência por parte do empreendedor em lidar com aspectos gerenciais do negócio. Essa resistência está relacionada ao fato de ele estar mais preocupado com a atividade-fim da startup e de entender esse envolvimento como limitador da sua atuação. Ao trazer seu conhecimento gerencial para a empresa, o IA pode requestionar prioridades, gerando melhorias no processo da organização. Os investidores que percebem que a capacidade gerencial do dono está de acordo com as suas expectativas, e que isso não the gerará riscos de perda financeira, acabam optando por se limitarem a contribuir financeiramente. No entanto, em casos em que a gestão da empresa está deficiente, os IAs tendem a assumir o controle a fim de protegerem o seu investimento (BARROS; TODA; RAMOS, 2016). 


\subsection{CAPITAL SOCIAL}

O capital social pode ser definido como: "[...] a soma dos recursos decorrentes da existência de uma rede de relações de reconhecimento mútuo institucionalizada em campos sociais" (MARTELETO; SILVA, 2004, p. 44). Esse capital se constitui no estabelecimento de trocas entre indivíduos, formando uma rede de relações que agregam recursos ou o acesso a eles. A formação de redes de relacionamento é de extrema importância não somente no início do empreendimento, mas também ao longo de toda a existência da organização, tornando-se um fator decisivo para o desenvolvimento da startup (NAHAPIET, 2014).

No Vale do Silício, os investidores de risco possuem a função de inserir os empreendedores nas chamadas "redes complexas", responsáveis por prover recursos para projetos inovadores da região. Se o empreendedor não estiver bem estabelecido em uma rede, receberá poucos recursos (FERRARY; GRANOVETTER, 2009). Muitas vezes, por meio de sua rede de relacionamento, o empreendedor consegue sinalizar confiança ao mercado. Essa sinalização ocorre por meio de um conjunto de laços sociais que forma um importante "banco" de credenciais, atestando seu status social e indicando os prováveis recursos a ele disponíveis. (NAHAPIET, 2014).

Os IAs, por serem empresários de sucesso ou então gestores experientes, possuem, em sua rede de relacionamento, muitos contatos para a obtenção de parcerias, auxiliando o empreendedor a conquistar fontes confiáveis que podem contribuir para o seu negócio. A partir do exposto, pode-se concluir que os IAs têm um importante papel na ampliação, ainda que modesta, da rede de contatos da empresa (BARROS; TODA; RAMOS, 2016).

\section{MÉTODO}

Para responder ao problema de pesquisa abordado no início deste trabalho, foi realizada uma pesquisa descritiva qualitativa de caráter exploratório. O caráter exploratório se justifica, pois, a literatura tangencia, mas não esclarece o problema de pesquisa proposto, uma vez que não foram encontradas obras que abordem, especificamente, as contribuições dos IAs às empresas.

A seleção dos participantes ocorreu de acordo com critérios preestabelecidos: 1) que os IAs tenham realizado investimentos em startups; e 2) que os empreendedores tenham recebido algum aporte de recursos originado de IAs. Um primeiro contato com pesquisadores, professores e gestores de incubadoras sobre a ideia da pesquisa indicou que a coleta de dados não seria fácil, pelo pouco interesse deste público específico em participar de pesquisas. Assim, decidiu-se pela técnica de snowball (ou "bola de neve", em 
tradução livre) para incrementar o volume de dados coletados (VAN METER, 1990). Nesse processo, um dos autores participou de um evento em novembro de 2016, onde foram obtidos os primeiros contatos de respondentes. Na medida em que foram sendo realizadas as entrevistas, mais respondentes foram sendo indicados, contatados e entrevistados.

A coleta de dados foi realizada por meio de entrevistas em profundidade com os investidores e gestores das startups. Foram entrevistadas onze pessoas, sendo quatro IAs e sete empreendedores que receberam Investimento Anjo. As entrevistas foram conduzidas nos meses de julho e agosto de 2017, e ocorreram por intermédio de encontros presenciais em locais escolhidos pelos entrevistados ou, quando não houve disponibilidade para tal, encontros online com uso de Skype. O perfil dos entrevistados, localizados na região metropolitana de Porto Alegre, está apresentado no Quadro 1.

\section{Quadro 1 - Identificação dos entrevistados}

\begin{tabular}{|l|l|l|}
\hline Identificação & Atuação & Formato do Investimento \\
\hline Entrevistado A & Investidor Anjo & Atua como investidor e consultor em bancas de pitchs \\
\hline Entrevistado B & Investidor Anjo & Atua como investidor individual e por meio de uma empresa \\
\hline Entrevistado C & Investidor Anjo & Atua como investidor por meio de uma empresa aceleradora \\
\hline Entrevistado D & Investidor Anjo & Atua como investidor individual e por meio de um grupo \\
\hline Entrevistado E & Empreendedor & Recebeu investimento de um IA \\
\hline Entrevistado F & Empreendedor & Recebeu investimento de um grupo de vinte e seis IAs \\
\hline Entrevistado G & Empreendedor & Recebeu investimento de um grupo com mais de vinte IAs \\
\hline Entrevistado H & Empreendedor & Recebeu investimento de um grupo de três IAs \\
\hline Entrevistado I & Empreendedor & Recebeu investimento de um IA \\
\hline Entrevistado J & Empreendedor & Recebeu investimento de um grupo de IAs \\
\hline Entrevistado K & Empreendedor & Recebeu investimento de um grupo de IAs \\
\hline
\end{tabular}

Fonte: elaborado pelos autores 
O roteiro de entrevistas abordou tópicos relativos aos objetivos propostos com base nas categorias teóricas identificadas na literatura e direcionados ao público-alvo desta pesquisa. O Quadro 2 apresenta os tópicos abordados na entrevista e os autores que os inspiraram.

\section{Quadro 2 - Tópicos abordados na entrevista}

\begin{tabular}{|c|c|}
\hline Tópicos e categorias teóricas & Referencial teórico \\
\hline Forma de atuação (individual ou em grupos) & (BESSANT; TIDD, 2011; MINEIRO et al., 2016) \\
\hline $\begin{array}{l}\text { Motivação para a escolha do projeto (ex.: interesse pelo } \\
\text { projeto, papel do retorno financeiro, empenho e capacidade do } \\
\text { empreendedor e equipe) }\end{array}$ & $\begin{array}{l}\text { (BARROS; TODA; RAMOS, 2016; BESSANT; TIDD, 2011; } \\
\text { BOTELHO; DIDIER; RODRIGUEZ, 2006; CARVALHO; } \\
\text { RIBEIRO; FURTADO, 2006; MASON; STARK, 2004; } \\
\text { SPINA, 2015; VANHAVERBEKE, 2006) }\end{array}$ \\
\hline $\begin{array}{l}\text { Necessidades dos empreendedores (capital financeiro, } \\
\text { conhecimento, networking, avaliação do projeto) }\end{array}$ & $\begin{array}{l}\text { (DORNELAS, 2008; FERRARY; GRANOVETTER, 2009; } \\
\text { SPINA, 2015) }\end{array}$ \\
\hline $\begin{array}{l}\text { Relacionamento com empreendedor (importância do } \\
\text { relacionamento, alinhamento de objetivos, construção da } \\
\text { confiança) } \\
\text { Negociação do acordo: } \\
\text { * Definição de regras } \\
\text { * Frequência e meios de comunicação } \\
\text { * Participação do investidor em decisões estratégicas e } \\
\text { operacionais } \\
\text { * Estabelecimento de índices de desempenho } \\
\text { * Previsão de saída do investidor }\end{array}$ & $\begin{array}{l}\text { (CARIS, 2006; DORNELAS, 2008; GRAY, 2008; GULATI; } \\
\text { GARGIULO, 1999; NOOTEBOOM, 2000; SPINA, 2015; } \\
\text { WOOLTHUIS; HILLEBRAND; NOOTEBOOM, 2005; } \\
\text { ZAHEER; MCEVILY; PERRONE, 1998) }\end{array}$ \\
\hline $\begin{array}{l}\text { Contribuições realizadas (questões levantadas nas } \\
\text { necessidades e que os investidores puderam sanar, } \\
\text { contribuições não previstas) }\end{array}$ & $\begin{array}{l}\text { (BARROS; TODA; RAMOS, 2016; BOTELHO; DIDIER; } \\
\text { RODRIGUEZ, 2006; JUDICE; BAÊTA, 2005; NAHAPIET, } \\
\text { 2014; SPINA, 2015) }\end{array}$ \\
\hline
\end{tabular}

\section{Fonte: Elaborado pelos autores}

Com o intuito de validar o procedimento de coleta de dados e identificar formas adequadas para sua execução, foi realizada uma entrevista piloto com um dos selecionados. Essa entrevista não revelou modificações necessárias no roteiro de entrevistas, ficando todos os tópicos bastante claros ao entrevistado. 
Por serem utilizadas questões abertas, na medida em que as entrevistas foram sendo realizadas, o entrevistador direcionou certos tópicos para melhor identificar padrões nos dados e sua aderência às categorias teóricas propostas. Desta forma, condizente com o caráter exploratório pretendido, não houve um enfoque estreito na condução das entrevistas, podendo os entrevistados revelarem sua realidade com maior grau de liberdade (ROESCH; BECKER; DE MELLO, 2000). A coleta de dados qualitativos resultou em quatro horas de áudio gravado e 10 páginas de transcrições. A gestão e o controle adequados dessas informações seguiram as indicações de Collis e Hussey (2005) para pesquisas qualitativas:

- Transformar todas as entrevistas realizadas em registro escrito, de forma que possam ser compreendidas por qualquer um que as leia;

- Assegurar-se de que todos os materiais foram citados, identificando origem e momento de coleta;

- Codificação dos dados, destinando um código para cada variável, conceito ou tema que se deseja identificar;

- Posterior à codificação, os dados podem ser agrupados em categorias, de acordo com padrões ou temas que surgiram;

- Redação de resumos referente a descobertas realizadas até o momento;

- Formar generalizações, confrontando-as com teorias já existentes;

- Realizar entrevistas até a certeza de que as generalizações que surgiram são suficientes para serem comparadas com as teorias já existentes.

De acordo com Gibbs (2009), os pesquisadores qualitativos devem transcrever suas entrevistas para produzir uma cópia digitada clara, de forma que seja possivel realizar a codificação dos dados mais facilmente. 0 autor também afirma que os códigos formam um foco para pensar no texto e suas interpretações, no entanto é necessário haver uma organização dos termos. A categorização é a forma mais comum para essa organização, facilitando o acesso e a comparação relativamente rápida de todos os dados. No processo de análise qualitativa, a escrita tem papel essencial, pois escrever sobre os dados auxilia no processo de reflexão para a realização do relatório, fornecendo evidências que vão moldando a análise dos dados.

Seguindo o processo de análise, os dados foram codificados e associados às categorias teóricas a fim de identificar os conceitos emergentes. $O$ resultado dessa análise está apresentado na seção a seguir. 


\section{ANÁLISE E DISCUSSÃO DOS RESULTADOS}

As seções a seguir irão abordar os questionamentos realizados e as respostas obtidas nas entrevistas, relacionando-as com a base teórica desta pesquisa.

Observou-se que a atuação dos IAs geralmente ocorre em grupo, embora dois deles também tenham realizado investimento individualmente por indicação de sua rede de contatos. Isso foi corroborado pela maioria dos empreendedores, que mencionaram receber investimento principalmente de grupos de investidores, já que investidores que atuam em grupo conseguem diluir os riscos associados ao investimento (MINEIRO et al., 2016). Redes de IAs trazem benefícios tanto para investidores, que podem compartilhar experiências e esforços na realização dos investimentos e na gestão da relação com o empreendedor, quanto para empreendedores, que podem sentir-se mais seguros ao apresentarem seus projetos para um grupo (SPINA, 2015).

\subsection{MOTIVAÇÕES PARA O INÍCIO DO PROJETO}

O encontro entre investidor e empreendedor geralmente ocorre em eventos ou a partir de empresas que intermediam o contato entre eles. Os empreendedores citaram a participação em eventos e rede de contatos, e dois deles mencionarem ter tido contato somente por processo seletivo de empresas.

\footnotetext{
Em eventos de mentoria e empreendedorismo, promovidos por entidades governamentais, com a apresentação do negócio, foram surgindo contatos com investidores e a indicação para captar investimento. (Entrevistado E).

Conheceu os investidores no mercado, sendo eles clientes, o empreendedor escolheu os investidores, devido ao perfil profissional de cada um, convidando-os para investirem no projeto. (Entrevistado H).
}

Embora Spina (2015) admita que indicações, eventos específicos em incubadoras e aceleradoras sejam formas usuais de contato entre empreendedor e investidor, o autor também aponta que a forma mais utilizada para o encontro entre eles têm sido a internet, por meio de sites de grupos ou empresas que recebem materiais dos empreendedores. Essa forma de contato, entretanto, não foi mencionada pelos respondentes. Entende-se que a proximidade geográfica induza a troca de conhecimento tácito e, no longo prazo, a formação de relações de confiança (VANHAVERBEKE, 2006). Assim, talvez por falta de uma demanda que exija a adoção de plataformas tecnológicas intermediadoras desses contatos, a presença física ainda seja preferida pelos entrevistados. 
Ao serem questionados sobre as motivações para a realização do investimento, os IAs mencionaram como importante: 1) o conhecimento sobre a área de atuação; 2) a propriedade intelectual com registros de patentes; 3) o retorno financeiro; 4) o potencial de crescimento; e 5) o empenho e a capacidade do empreendedor e equipe. Cada um desses tópicos é abordado a seguir.

O conhecimento sobre a área de atuação foi apontado por Botelho, Didier e Rodriguez (2006) como fator favorável para identificar parcerias para os empreendedores. Em linha com a literatura, é possivel que os IAs entrevistados apreciem a chance de retomar o conhecimento adquirido ao longo de sua vida empresarial, aconselhando e orientando empreendedores no desenvolvimento de suas empresas.

Conforme Bessant e Tidd (2011) um dos critérios para a realização do investimento consiste em patentes registradas. $O$ registro de patentes foi considerado um item importante para a avaliação positiva do empreendimento por um dos investidores, cuja fala está a seguir:

Prefiro projetos com produtos independentes de empreendedor, de preferência com propriedade intelectual e registros de patentes. Não invisto em projetos de áreas desconhecidas. Prefiro investir em empresas de origem acadêmica (Entrevistado B).

A escolha baseada em capacidade de crescimento do projeto foi apontada por todos os investidores, almejando retornos financeiros com o desenvolvimento do negócio, "avalio se o negócio tem perspectiva de crescimento, se o setor tem potencial" (Entrevistado D). Conforme Barros, Toda e Ramos (2016) os IAs investem com o intuito da valorização da empresa que consequentemente resultará em ganho de capital financeiro. Quanto a isso, o Entrevistado B foi enfático: "Não invisto em projetos que não tiverem performance", ou seja, prefere empresas que já tenham algum histórico de rentabilidade. De acordo com Carvalho, Ribeiro e Furtado (2006), o potencial de crescimento e elevada possibilidade de retorno com o intuito de justificar os custos, a baixa liquidez e os riscos associados são requisitos analisados para ocorrer o investimento.

Mason e Stark (2004) observam que os IAs costumam valorizar a capacidade do grupo empreendedor e sua propensão ao relacionamento, sendo provável que se estabeleça uma participação bastante ativa na gestão do negócio, é fundamental existir empatia entre as partes. Harrison, Botelho e Mason (2016) chegam a afirmar que as características do empreendedor podem ser mais importantes que o negócio em si. Nessa linha, outro tópico mencionado pela maioria dos investidores está relacionado ao perfil do empreendedor. Os IAs, objetivando facilitar a construção de um relacionamento com os empreendedores, avaliam as suas características pessoais. Conforme relata o Entrevistado C: "Principalmente capacidade do empreendedor, [...] o empreendedor precisa demonstrar vontade." Os empreendedores, por sua vez, escolheram o Investimento Anjo pela melhor razão custo/benefício apresentada pelos IAs, bem como 
pelas contribuições diferenciadas que foram oferecidas. Além disso, a localização geográfica também foi apontada como importante nessa escolha.

Spina (2015) caracteriza o Investimento Anjo como uma atividade que transcende o aspecto financeiro do negócio, devendo o investidor ter interesse pelo negócio para se dedicar junto ao empreendedor. Nessa linha, todos os empreendedores entrevistados mencionaram ter interesse nas contribuições diferenciadas que thes foram oferecidas. O interesse, para além do capital financeiro, consistiu em conhecimento complementar, contatos para formação de parcerias, fornecedores e clientes. A fala do Entrevistado $F$ tipifica essa questão:

[...] captamos recursos com IAs por acreditarmos ser uma fonte de Smart Money, podendo obter conexões, contatos, buscar conhecimento técnico, conhecimento especificamente relacionado a meios de converter experiências de clientes em compras. (Entrevistado F).

A proximidade geográfica com o investidor também foi um fator de escolha levantado por um empreendedor. Os empreendedores tiveram acesso aos investidores por meio de eventos e rede de contato, escolhendo essa forma de captação de recursos, por ser considerado melhor custo benefício mediante potenciais contribuições diferenciadas oferecidas, surgindo também o fato da proximidade geográfica. Como aponta o Entrevistado K: "[...] os investidores estavam mais próximos da região [...]". Vanhaverbeke (2006) comenta que a proximidade pode ser benéfica para a troca de conhecimento e formação de redes de relacionamento, o que possivelmente ocorre devido à maior proximidade cognitiva entre os atores, favorecendo a capacidade absortiva (FOSFURI; TRIBÓ, 2008).

\subsection{NECESSIDADES DOS EMPREENDEDORES}

A seguir serão abordadas as necessidades dos empreendedores, percebidas por eles mesmos e pelos investidores, ao buscar Investimento Anjo.

Os empreendedores, muitas vezes, não possuem recursos ou competências para executar ações preventivas para minimizar os riscos do negócio. Nesse sentido, os IAs podem contribuir com sua experiência. Os investidores relataram que percebem como necessidade dos empreendedores: capital financeiro, conhecimento, networking, feedback em relação ao projeto e espaço para trabalho.

Naturalmente citados como necessidade básica, os recursos financeiros foram apontados por todos os investidores como uma demanda dos empreendedores, chegando a ser mencionado por um IA como a 
principal demanda. No entanto, para que os negócios saiam do papel, é necessário também haver talento e know-how (DORNELAS, 2008).

O conhecimento foi mencionado pela metade dos investidores, principalmente em relação à gestão, mas também em relação a finanças, operações e prospecção de mercado. Judice e Baêta (2005) afirmam que na medida em que as startups se desenvolvem, necessitam de um melhor gerenciamento, sendo que a inabilidade do empreendedor nessa questão pode ser prejudicial à empresa.

Outro ponto bastante relevante foi o networking. O Entrevistado C menciona como necessidade os "contatos para parcerias e auxílio na abertura de portas".

O Entrevistado D evidencia a busca tanto de conhecimento quanto de recursos financeiros e redes de contato: "Capital financeiro associado a conhecimento, procurando investidor que tenha relacionamento no segmento", facilitando assim futuras parcerias ou até mesmo a venda da empresa para redes maiores. A inserção de empreendedores do Vale do Silício em redes de contato é essencial para obtenção de recursos, o que não ocorre quando estão fora destas redes (FERRARY; GRANOVETTER, 2009).

Um benefício adicional das redes de contato diz respeito à sinalização obtida quanto à qualidade do projeto. Por exemplo, um investidor entrevistado comenta que "muitos empreendedores apresentam seu projeto e buscam verificar por meio de conversas informais se o seu projeto está bom, buscando feedback que possa melhorar o negócio" (Entrevistado D). Dornelas (2008) reforça essa ideia quando afirma que os empreendedores, quando estão iniciando suas empresas, necessitam testar suas ideias e buscar opiniões de empreendedores mais experientes, identificando assim se o seu produto é aceito.

Outro recurso demandado pelos empreendedores foi trazido pelo Entrevistado C como "disponibilidade de espaço para a empresa". Esse investidor mencionou que disponibilizava espaço compartilhado para os empreendedores se instalarem, diminuindo os custos com estrutura.

As necessidades apontadas pelos empreendedores convergiram para aquelas já mencionadas pelos investidores: capital financeiro, conhecimento, networking e espaço para trabalho.

Naturalmente, o capital financeiro foi apontado por todos como uma necessidade ao buscar por Investimento Anjo, chegando a ser indicado por um empreendedor como a única necessidade. Embora seja o principal motivo para essa busca, o acesso aos demais recursos, mesmo que inicialmente não pretendidos, também acaba beneficiando os empreendedores. Isso fica evidente quando Judice e Baêta (2005) sugerem que as organizações financiadas por investidores-anjo têm maiores chances de sucesso e sobrevida, comparativamente àquelas que não receberam esse tipo de investimento.

Nesse sentido, o conhecimento foi citado como necessário pela maioria dos respondentes, especialmente aquele relativo à gestão e à área específica do negócio. As startups são empresas nascentes que necessitam lançar produtos rapidamente com preços atrativos para se manterem competitivas, dessa 
forma o conhecimento torna-se fator de extrema importância. Essa necessidade levou os empreendedores a buscarem principalmente investidores que possuem experiência de mercado na área de atuação da empresa. Algumas falas evidenciam esse ponto:

\footnotetext{
Conhecimento de gestão para organização das finanças, estabelecimento de indicadores para melhores tomadas de decisão. (Entrevistado E).

Conhecimento na área de jogos, tecnologia, na área de finanças, buscando formas mais assertivas de investimento e na área de marketing. (Entrevistado H).
}

A formação de uma rede de contatos foi apontada por mais da metade dos entrevistados, objetivando formar parcerias com fornecedores e clientes. Eventualmente, os próprios investidores podem se tornar clientes do negócio. Isso evidencia que o capital social é importante em todas as fases do ciclo empreendedor. Por intermédio das redes sociais os empreendedores obtêm conhecimento, recursos e apoio para seus projetos (NAHAPIET; GHOSHAL, 1998).

\footnotetext{
A formação de parcerias e auxílio com clientes, o investidor possui contatos e pode indicar os serviços da empresa tanto para parceiros, quanto para fornecedores e clientes. (Entrevistado E).

Formação de parcerias; formação de clientes, próprios investidores podem ser clientes. (Entrevistado G).
}

Embora menos citado, o espaço físico para trabalho também foi abordado por dois empreendedores como uma necessidade que os investidores poderiam suprir. Isso demonstra que a diversidade de recursos a serem investidos na relação é ampla e merece ser explorada.

Em relação às necessidades percebidas pelos investidores e apontadas pelos empreendedores, pode-se perceber que a visão de ambos se assemelha, sendo mencionados o capital financeiro, conhecimento, networking e espaço para trabalho pelos dois grupos de respondentes.

\subsection{CONSTRUÇÃO DO RELACIONAMENTO}

O relacionamento torna-se um ponto de atenção, uma vez que os objetivos principais de cada parte estão alinhados (SCOTT; GABLE, 1997; YAN; DOOLEY, 2013). Os IAs precisam ter segurança para aportar recursos, ao mesmo tempo em que o empreendedor quer ter ao seu lado pessoas que lhe ajudem a construir o seu negócio. A fim de evitar conflitos é necessário definir regras, determinando um contrato com direitos e deveres de cada parte, assim estabelecendo uma comunicação aberta e amigável (SPINA, 2015). 
Os entrevistados foram questionados sobre o alinhamento de objetivos, fechamento do contrato e como ocorreu a negociação da parceria, também foram questionados a respeito da relevância do desenvolvimento da relação e a confiança entre IA e empreendedor.

Os investidores relacionaram o alinhamento de objetivos à seleção do projeto alvo de investimento, resultando no acordo. $O$ processo ocorre com a escolha das propostas, alguns casos decorrem por meio de processo seletivo onde há pré-requisitos estabelecidos. Então, empreendedor e IA têm um encontro presencial para tirar dúvidas, prevendo um contrato do negócio. Nesse momento, ambas as partes expõem as suas expectativas e com base nisso são gerados os termos de direitos e deveres de cada um.

[...] o investidor recebe um resumo do investimento e analisa o que está dentro das possibilidades, antes de realizar uma entrevista. Na entrevista são discutidos os termos de contrato abordando direitos e deveres, deixando claros os ônus e bônus de cada parte. (Entrevistado B)

O alinhamento entre as partes pode ser um desafio, sendo necessário integrar ambas as visões para iniciar uma relação confiável que seja vantajosa para os atores envolvidos (GRAY, 2008). O encontro presencial auxilia também na percepção do perfil do empreendedor, no sentido de identificar se as características pessoais vão de encontro com o que o IA procura, na expectativa de que a relação entre eles seja tranquila.

[...] é realizada uma entrevista pessoal com o empreendedor, onde se perguntam questões sobre pretensões futuras e já se vai percebendo como é o seu perfil, caso se identifique que não se está de acordo com os princípios expostos por ele, o acordo não acontece. (Entrevistado A).

Essa interação visa, também, promover maior confiança entre as partes, pois melhora a previsibilidade em relação ao comportamento da outra parte e a expectativa em relação a sua boa vontade (ZAHEER; MCEVILY; PERRONE, 1998). Assim, o bom relacionamento acaba se tornando resultado de uma negociação transparente permeada pela confiança, onde as partes deixam claros os seus objetivos e percebem que irão conseguir ter um bom diálogo, realizando um contrato onde há equilíbrio de interesses fornecendo segurança para ambos. O Entrevistado A ilustra o que ocorre, caso contrário:

[...] geralmente quando se percebe que o empreendedor não estará adepto das ideias do investidor, dificultando o relacionamento, não se realiza acordo. (Entrevistado A). 
Todos os investidores mencionaram o bom relacionamento como importante para o andamento do negócio. Os empreendedores mostraram o mesmo entendimento, relacionando o alinhamento de objetivos a um diálogo para o estabelecimento de direitos e deveres de cada parte, resultando na formalização de um contrato ou acordo informal. A maioria dos empreendedores mencionou já conhecer previamente o IA, desta forma já subsidiando uma futura relação de confiança. O conhecimento das etapas que pautariam o relacionamento entre eles também já existia, por meio da participação em um processo seletivo, estando o empreendedor ciente de como funcionaria a captação de recursos. Conforme destaca o Entrevistado H:

[...] os investidores eram conhecidos, sendo meus clientes, então os escolhi para fazer parte do negócio, convidando-os para investirem no projeto. (Entrevistado H).

Spina (2015) sugere que os empreendedores devem fazer uma seleção dos investidores para o seu negócio, escolhendo o IA que possa Ihe trazer melhores benefícios, podendo ser desastroso aceitar um investimento somente pela melhor oferta financeira, expondo-se ao risco de ocorrer futuros conflitos de interesse.

$O$ envolvimento do investidor nas rotinas da empresa depende muitas vezes do empreendedor, que pode limitar sua participação (BARROS; TODA; RAMOS, 2016). Entretanto, nos casos em que já havia uma relação de confiança, a sociedade entre eles foi estabelecida de forma a possibilitar ao IA maior liberdade de atuação na gestão do negócio. Nesse sentido, o Entrevistado $\mathrm{H}$ menciona que "[...] existe um pequeno conselho, onde as melhores ideias são aderidas não importando o peso de cada sócio. As tarefas são deliberadas".

Já nas empresas em que o investidor não participa do quadro social, seu papel se caracteriza como conselheiro, não sendo obrigatória a adesão das sugestões propostas por parte do empreendedor. 0 Entrevistado F destaca como isso ocorre:

Estabeleceu-se que a cada 3 meses seriam enviados relatórios onde constam os números referente a índices estabelecidos, os investidores têm liberdade de questionar números a qualquer hora, mas os investidores não possuem poder de decisão, são vistos como aconselhadores. (Entrevistado F).

Mesmo nos casos onde a participação dos investidores é limitada, os entrevistados mencionaram a importância das sugestões dos investidores, acreditando ser de muita valia para o negócio.

O relacionamento foi citado pela maioria dos entrevistados como fundamental para o andamento do negócio, em razão dos benefícios percebidos. Embora em alguns casos a participação do investidor não seja tão ativa, ainda assim os empreendedores percebem ser importante manter um canal aberto 
para troca de ideias. Em síntese, a construção de um bom relacionamento entre IA e empreendedor gera bons resultados ao negócio, sendo uma união muito benéfica quando os objetivos são alinhados com transparência e seriedade.

\subsection{CONTRIBUIÇÕES DOS INVESTIDORES}

Ao longo desta pesquisa, pôde-se identificar que os empreendedores procuram o Investimento Anjo a fim atender as suas necessidades em vários aspectos do negócio. Isso ficou evidenciado quando os entrevistados foram questionados sobre o resultado da formação desta parceria. As contribuições levantadas pelos investidores foram: capital financeiro, conhecimento, networking, sinalização de que o projeto é confiável e espaço para trabalho.

Todos os investidores mencionaram a realização de aporte de capital financeiro, sendo esta também uma das principais contribuições percebidas pelos empreendedores e apontada como principal contribuição pela literatura (BARROS; TODA; RAMOS, 2016).

A respeito do conhecimento, os IAs indicaram o auxílio com a gestão do negócio referente a aspectos de finanças, recursos humanos e planejamento. Essa contribuição está em linha com o que aponta a literatura sobre o tema, indicando que quando o investidor entra na empresa, ele formata, reestrutura e racionaliza o plano de negócios e as tarefas administrativas e gerenciais, conduzindo de forma efetiva o crescimento da organização (JUDICE; BAÊTA, 2005). No caso desta pesquisa, percebe-se que os investidores também atuaram na atividade-fim da empresa com seu conhecimento específico, quando o seu know-howera aderente a essa atividade. Fica evidente que os IAs atuam buscando retornos financeiros, mas também com o intuito de retornar o seu conhecimento, resultado de experiências empreendedoras, para aconselhar e orientar outros empreendedores no desenvolvimento de suas empresas (BOTELHO; DIDIER; RODRIGUEZ, 2006).

Outra contribuição mencionada se refere ao networking. Sobre isso, os investidores mencionaram contribuir com a "abertura de portas", no sentido de indicar contatos, formar parcerias e estabelecer uma cartela de clientes. Para os empreendedores, o acesso a conexões estratégicas para o negócio promovido pelo investidor é fundamental para o desenvolvimento da empresa. O relato do Entrevistado Cilustra esse ponto:

Abertura de portas, conectar os empreendedores com clientes e parceiros de negócios, que dificilmente seria possível sem a intermediação do investidor. (Entrevistado C). 
Esses laços sociais estabelecidos podem também indicar confiança ao mercado, constituindo um importante banco de credenciais e facilitando o acesso a recursos em todos os sentidos (NAHAPIET, 2014). A sinalização de que o projeto é confiável pode ser evidenciada no relato do Entrevistado A. Segundo ele, o fato de ter investido em um projeto atribuiu maior credibilidade a este, influenciando outros investidores a entrarem no negócio.

Além dessas contribuições, o espaço físico para trabalho foi apontado pelo Entrevistado C, que tem à disposição um espaço de coworking para empreendedores fornecido pelo investidor.

O relato dos investidores, descrito acima, vai ao encontro da percepção dos empreendedores, apresentado a seguir.

O capital financeiro foi apontado em unanimidade pelos empreendedores como uma importante contribuiçãa dos IAs. No entanto, muitas vezes isso não é suficiente para o desenvolvimento do projeto. Investimentos são essenciais, mas a eficiência em sua utilização é fator preponderante, de forma que outros tipos de contribuição devem complementar o recurso financeiro.

O conhecimento, por exemplo, foi mencionado por todos os empreendedores. Eles apontaram diversas áreas em que a mentoria dos IAs foi de grande ajuda, citando conhecimentos em relação a gestão estratégica, finanças, marketing, expansão e captação de clientes, e mesmo aqueles conhecimentos específicos da área de atuação da empresa, como mencionado pelos investidores. Os relatos dos entrevistados $\mathrm{H}$ e I ilustram esse ponto:

Aporte tecnológico, conhecimento técnico tecnológico na área de jogos; Conhecimento de gestão, principalmente financeiro; Conhecimento na área de marketing. (Entrevistado H). [...] Auxílio nas formas de expansão da empresa, conhecimento de gestão. (Entrevistado I).

A formação de redes de relacionamento também foi mencionada pela maioria dos respondentes como uma contribuição, representando um auxílio bastante importante. O Entrevistado G comenta, por exemplo, que: "Desde o momento que receberam auxílio de investimento já perceberam muitas conexões, perspectiva de clientes".

O respondente E aponta que o investidor contribui também com força de trabalho, realizando inclusive atividades de rotina dentro da empresa. Barros, Toda e Ramos (2016) mencionam essa forma de atuação, no sentido de que alguns investidores, além de assumirem posições no conselho ou atuarem como consultores, podem até mesmo participar em atividades operacionais da empresa.

Dois empreendedores também mencionaram o espaço para trabalho como outro auxílio prestado pelos investidores. 
Assim, a visão das partes entrevistadas, investidores e empreendedores, traz aspectos bastante semelhantes, apontando que as principais contribuições se referem a capital financeiro, conhecimento e networking. Os investidores, de um lado, buscam estar abertos a auxiliar os empreendedores suprindo suas necessidades, com o intuito de fazer o negócio crescer e dar resultado, sendo benéfico para ambos, empreendedor e investidor. Os empreendedores, de outro lado, afirmam receber apoio de várias formas, sendo muito bem aceitas as contribuições que os IAs podem proporcionar. No entanto, nos casos em que há uma relação mais distante, esse auxílio pode acontecer de maneira mais moderada. As contribuições mencionadas tanto pelos investidores quanto pelos empreendedores indicam que os IAs fazem um investimento com valor agregado, o chamado smart-money (ou "dinheiro inteligente", em tradução nossa), pois aplicam, além de recursos financeiros, conhecimento, experiência e relacionamento, para apoiar o empreendedor (SPINA, 2015). O Quadro 3 apresenta uma síntese dos resultados, onde estão expostas as questões abordadas nas entrevistas, a visão dos IAs e dos empreendedores. 
Quadro 3 - Síntese dos Resultados da Análise

\begin{tabular}{|c|c|c|}
\hline Questões abordadas & Visão dos IAs & Visão dos Empreendedores \\
\hline $\begin{array}{l}\text { Forma de atuação } \\
\text { dos IAs e meios } \\
\text { de contato com os } \\
\text { empreendedores. }\end{array}$ & $\begin{array}{l}\text { Atuam principalmente em grupo, individualmente } \\
\text { de forma eventual; } \\
\text { Investimentos individuais, geralmente são } \\
\text { resultados de indicações; } \\
\text { Eventos ou empresas, são os maiores pontos de } \\
\text { encontro. }\end{array}$ & $\begin{array}{l}\text { As formas de contato ocorreram por } \\
\text { meio de: eventos, processos seletivos, } \\
\text { indicações, transações de mercado. }\end{array}$ \\
\hline $\begin{array}{l}\text { Motivações para a } \\
\text { formação da parceria }\end{array}$ & $\begin{array}{l}\text { Conhecimento sobre a área de atuação; } \\
\text { Propriedade intelectual com registros de patentes; } \\
\text { Retorno financeiro; } \\
\text { Potencial de crescimento; } \\
\text { Empenho e capacidade do empreendedor e } \\
\text { equipe. }\end{array}$ & $\begin{array}{l}\text { Melhor custo benefício apresentado; } \\
\text { Potenciais contribuições diferenciadas } \\
\text { oferecidas; } \\
\text { Localização geográfica. }\end{array}$ \\
\hline $\begin{array}{l}\text { Necessidades dos } \\
\text { empreendedores }\end{array}$ & $\begin{array}{l}\text { Capital financeiro; } \\
\text { Conhecimento em gestão e específico do negócio; } \\
\text { Networking; } \\
\text { Feedback em relação ao projeto; } \\
\text { Espaço para trabalho. }\end{array}$ & $\begin{array}{l}\text { Capital financeiro; } \\
\text { Conhecimento em gestão e específico do } \\
\text { negócio; } \\
\text { Networking; } \\
\text { Espaço para trabalho. }\end{array}$ \\
\hline $\begin{array}{l}\text { Construção do } \\
\text { relacionamento com o } \\
\text { empreendedor }\end{array}$ & $\begin{array}{l}\text { Alinhamento de objetivos por meio da seleção do } \\
\text { projeto; } \\
\text { Construção da confiança, identificando se os } \\
\text { valores e princípios da outra parte estão de } \\
\text { acordo; } \\
\text { Elaboração do contrato com direitos e deveres de } \\
\text { cada parte, determinando a forma de participação } \\
\text { do investidor. }\end{array}$ & $\begin{array}{l}\text { Construção da confiança; } \\
\text { Alinhamento de objetivos por meio } \\
\text { de diálogo para o estabelecimento } \\
\text { de direitos e deveres de cada parte, } \\
\text { determinando a forma de participação do } \\
\text { investidor, resultando na formalização do } \\
\text { contrato ou não, ocorrendo um caso de } \\
\text { investimento informal. }\end{array}$ \\
\hline $\begin{array}{l}\text { Importância do } \\
\text { relacionamento }\end{array}$ & Fundamental para o andamento do negócio. & $\begin{array}{l}\text { Fundamental para o andamento do } \\
\text { negócio, quando há um contato maior } \\
\text { com os investidores. }\end{array}$ \\
\hline $\begin{array}{l}\text { Contribuições dos } \\
\text { investidores }\end{array}$ & $\begin{array}{l}\text { Capital financeiro; } \\
\text { Conhecimento; } \\
\text { Networking; } \\
\text { Sinalização de que o projeto é confiável; } \\
\text { Espaço para trabalho. }\end{array}$ & $\begin{array}{l}\text { Capital financeiro; } \\
\text { Conhecimento; } \\
\text { Networking; } \\
\text { Força de trabalho; } \\
\text { Espaço físico para realizar as atividades } \\
\text { da empresa. }\end{array}$ \\
\hline
\end{tabular}

Fonte: Elaborado pelos autores a partir das entrevistas 
É possivel identificar que, de maneira geral, os IAs oferecem e proporcionam contribuições bastante significativas do ponto de vista de ambos, empreendedores e investidores, e que há uma intenção em estabelecer um bom relacionamento, influenciando de forma considerável para o sucesso do negócio. Desta forma, os IAs podem ser considerados fomentadores do empreendedorismo e consequentemente do desenvolvimento econômico do país, gerando inovação por meio do auxílio prestado às startups.

\section{CONSIDERAÇÕES FINAIS}

O Investimento Anjo vem ganhando força no mercado e, apesar de ainda ser pouco conhecido, está se tornando uma importante fonte de capital para empreendedores que desejam captar recursos para seus negócios, especialmente aqueles em fase inicial. O estímulo ao empreendedorismo deve ser uma preocupação social, especialmente dos órgãos públicos, a fim de promover o desenvolvimento econômico do país, sendo de extrema importância na situação atual. O Investimento Anjo acaba fomentando o empreendedorismo, de forma privada, auxiliando startups nas fases mais difíceis.

O objetivo geral deste estudo consistiu em verificar a influência do IA no desenvolvimento de startups, identificando possíveis contribuições (ou barreiras) para os empreendedores. O referencial teórico abordou como se desenvolvem as startups e o papel dos IAs nesse processo, discutindo a sua potencial contribuição aos empreendedores. O material bibliográfico consultado trouxe a ideia de que o principal recurso almejado pelos empreendedores era capital de risco. Baseado nisso, um roteiro de entrevistas foi desenvolvido para verificar essas contribuições junto a investidores-anjo e empreendedores.

Como visto nesse artigo, os recursos financeiros ainda se mantêm como principal aporte dos IAs, mas a contribuição desses atores em outras áreas de desenvolvimento das startups também se mostra significativa. Percebe-se que, tanto na visão dos IAs quanto dos empreendedores, as principais contribuições proporcionadas consistem em: aporte financeiro, mentoria e suporte com rede de contatos, além de outros auxílios mencionados, como espaço físico para trabalho e feedbacks sobre o projeto. Identificou-se, no discurso dos empresários, uma grande abertura à troca de conhecimentos, tornandose uma motivação para os empreendedores realizar o negócio com investidores mais experientes, que apresentassem potenciais contribuições diferenciadas. Identificou-se, também, um motivador para a realização do acordo com o investidor que não havia sido abordado na literatura consultada: a localização geográfica. Assim, a prática encontrada nesse ambiente empírico se aproxima do conceito de smartmoney (SPINA, 2015), ou seja, um investimento em que os empreendedores recebem capital de risco, mas também se beneficiam com o conhecimento e experiências que o IA pode Ihe transmitir, além de ter acesso a contatos por intermédio do investidor. 
O estudo pode contribuir para essa modalidade de investimento, na medida em que aponta as contribuições atualmente praticadas e convida a uma reflexão sobre recursos adicionais, como espaços de trabalho, aos quais os IAs podem oferecer acesso e se diferenciar das demais modalidades de investimento. Entende-se que a principal contribuição teórica se constitui na condução de um estudo em uma área com escassa produção científica, além do questionamento acerca das possibilidades de contribuição dos IAs, que podem ser ampliadas levando em conta o acesso a recursos adicionais, conforme já mencionado.

Embora ainda haja certa escassez de material teórico em relação ao tema investidores-anjo, observase que este tema vem tomando força, devido à sua importância para o estímulo ao empreendedorismo e, consequentemente, ao desenvolvimento econômico. Pela dificuldade de acesso aos entrevistados e utilização da técnica de snowball para indicação das pessoas que poderiam contribuir com esse estudo, não é possivel generalizar as conclusões às quais se chegou aqui.

Sugere-se que futuros estudos verifiquem de forma mais aprofundada esses resultados, conduzindo estudos quantitativos mais abrangentes. Outras possibilidades de direcionamento de pesquisa incluem investigar diferenças nas contribuiç̧ões entre investimentos realizados por intermédio de IAs individuais, em grupo e por incubadoras, relacionando o tempo de investimento com a percepção dos empreendedores quanto às contribuições para o desenvolvimento da organização, averiguando também como empresas que receberam Investimento Anjo se desenvolveram em comparação com as empresas que não receberam.

\section{REFERÊNCIAS}

BALDASSI, D.; CRISPIM, S. Fundos de Capital de Risco: Suporte Para Romper as Barreiras de Entrada.

Gestão e Regionalidade, v. 25, n. 73, p. 101-110, 2009.

BARNEY, J. B.; HANSEN, M. H. Trustworthiness as a Source of Competitive Advantage. Strategic Management Journal, v. 15, p. 175-190, 1994.

BARROS, G. E. DE; TODA, F. A.; RAMOS, A. DA C. A Atuação de Investidores-Anjo em Empresas Investidas: Um Estudo Exploratório do Estado do Rio de Janeiro. IX Encontro de Estudos Sobre Empreendedorismo e Gestão de Pequenas Empresas. Anais...Passo Fundo, RS: 2016

BENVENUTTI, M. Incansáveis: Como empreendedores de garagem engolem tradicionais corporações e criam oportunidades transformadores. São Paulo, SP: Editora Gente, 2016.

BESSANT, J.; TIDD, J. Innovation and Entrepreneurship. [s.I: s.n.]. v. 31. 
BOTELHO, A. J. J.; DIDIER, D.; RODRIGUEZ, M. V. R. Impulsionando o Take-off da Inovação no Brasil: 0 Investidor Anjo. Encontro Anual da ANPAD. Anais...Salvador, Bahia: 2006

CALVOSA, M.; FREITAS, J. ANGEL INVESTOR: Empreendedorismo fomentado através de uma nova modalidade de investidor. Revista Cadernos de Administração, v. 1, n. 2, p. 1-18, 2008.

CARIS, J. L. Relacionamento Investidor Informal/Empreendedor no Brasil: Estudo de Casos. [s.I.] Universidade Federal do Rio de Janeiro, 2006.

CARVALHO, A. G. DE; RIBEIRO, L. DE L.; FURTADO, C. V. A indústria de Private Equity e Venture Capital: primeiro censo brasileiro. São Paulo, SP: Saraiva, 2006.

CGEE, C. DE G. E E. E. Capital de Risco e Desenvolvimento Tecnológico no Brasil: Experiência Recente e Perspectivas. [s.l: s.n.]. Disponível em: <http://www.cgee.org.br/arquivos/estudo013_03.pdf>.

COLLIS, J.; HUSSEY, R. Pesquisa em Administração - Um Guia Prático para Alunos de Graduação e Pós-Graduação. 2. ed. Porto Alegre: Bookman, 2005.

DACIN, T.; REID, D.; RING, P. S. Alliances and Joint Ventures: The role of partner selection from an embeddedness perspective. In: CROPPER, S. et al. (Eds.). . The Oxford Handbook of Inter-Organizational Relations. New York: Oxford Press, 2008.

DORNELAS, J. C. A. Empreendedorismo: Transformando ideias em negócios. Rio de Janeiro, RJ: Campus, 2008.

DOZ, Y. L.; HAMELL, G. A Vantagem das alianças: a arte de criar valor através de parcerias. Rio de Janeiro, RJ: Qualitymark, 2000.

FERRARY, M.; GRANOVETTER, M. The role of venture capital firms in Silicon Valley's complex innovation network. Economy \& Society, v. 38, n. 2, p. 326-359, 2009.

FOSFURI, A.; TRIBÓ, J. A. Exploring the antecedents of potential absorptive capacity and its impact on innovation performance. Omega, v. 36, n. 2, p. 173-187, 2008.

GIBBS, G. Análise de dados qualitativos: coleção pesquisa qualitativa. Porto Alegre, RS: Bookman Editora, 2009.

GRAY, B. Intervening to Improve Inter-Organizational Partnerships. In: CROPPER, S. et al. (Eds.). . The 0xford Handbook of Inter-Organizational Relations. New York: Oxford Press, 2008. 
GULATI, R.; GARGIULO, M. Where do Interorganizational Networks Come From? American Journal of Sociology, v. 104, n. 5, p. 1439-1493, 1999.

HARRISON, R. T.; BOTELHO, T.; MASON, C. M. Patient capital in entrepreneurial finance: A reassessment of the role of business angel investors. Socio-Economic Review, 2016.

HORBUCZ, K. DA S. N. Financiamento à inovação: investigação dos atributos considerados por fundos de capital anjo no processo de decisão de investimento. [s.l.] Universidade Federal do Paraná, 2015.

JUDICE, V. M. M.; BAÊTA, A. M. C. Modelo empresarial, gestão de inovação e investimentos de venture capital em empresas de biotecnologia no Brasil Revista de Administração Contemporânea scielo, 2005.

MARTELETO, R. M.; SILVA, A. B. DE O. Redes e capital social: o enfoque da informação para o desenvolvimento local. Ciência da informação, v. 33, n. 3, p. 41-49, 2004.

MASON, C.; STARK, M. What do investors look for in a business plan? A comparison of the investment criteria of bankers, venture capitalists and business angels. International Small Business Journal, v. 22, n. 3, p. 227-248, 2004.

MINEIRO, A. C. et al. Investigação do potencial de um polo de inovação para a criação de uma rede de investidores-anjo a partir de seu ecossistema empreendedor. Reista de Administração, Contabilidade e Economia da FUNDACE, v. 7, n. 1, 2016.

NAHAPIET, J. O Papel do Capital Social em Relacionamentos Interorganizacionais. In: CROPPER, S. et al. (Eds.). . Handbook de Relações Interorganizacionais. Porto Alegre, RS: Bookman, 2014. p. 521-545.

NAHAPIET, J.; GHOSHAL, S. Social Capital, Intellectual Capital, and the Organizational Advantage. The Academy of Management Review, v. 23, n. 2, p. 242-266, 1998.

NOOTEBOOM, B. Institutions and Forms of Co-ordination in Innovation Systems. Organization Studies (Walter de Gruyter GmbH \& Co. KG.), v. 21, n. 5, p. 915, 2000.

PAVANI, C. O Capital de Risco no Brasil: Conceito, Evolução e Perspectivas. Rio de Janeiro, RJ: [s.n.].

RING, P. S.; VAN DE VEN, A. H. Structuring cooperative relationships between organizations. Strategic Management Journal, v. 13, n. 7, p. 483-498, 1992.

ROESCH, S. M. A.; BECKER, G. V.; DE MELLO, M. I. Projetos de estágio e de pesquisa em administração: guia para estágios, trabalhos de conclusão, dissertações e estudos de caso . [s.l.] Editora Atlas SA, 2000. 
SCHUMPETER, J. A. The theory of economic development: An inquiry into profits, capital, credit, interest, and the business cycle. [s.I.] Transaction publishers, 1934. v. 55

SCOTT, J. E.; GABLE, G. Goal Congruence, Trust, and Organizational Culture: Strengthening Knowledge Links. Proceedings of the Eighteenth International Conference on Information Systems. Anais...: ICIS ' 97. Atlanta, GA, USA: Association for Information Systems, 1997Disponivel em: <http://dl.acm.org/citation. cfm?id=353071.353109>

SPINA, C. A. Investidor Anjo: Como Conseguir Investidores Para Seu Negócio. São Paulo, SP: nVersos, 2015.

STEWART, T. A. Capital intelectual: a nova vantagem competitiva das empresas. [s...] Campus Rio de Janeiro, 1998. v. 2

VAN METER, K. M. Methodological and design issues: techniques for assessing the representatives of snowball samples. NIDA Research Monograph, v. 98, n. 51.40, p. 31-43, 1990.

VANHAVERBEKE, W. The Interorganizational Context of Open Innovation. In: CHESBROUGH, H.; VANHAVERBEKE, W.; WEST, J. (Eds.). . Open Innovation: Researching a New Paradigm. New York: Oxford University Press, 2006.

WOOLTHUIS, R. K.; HILLEBRAND, B.; NOOTEBOOM, B. Trust, Contract and Relationship Development. Organization Studies (01708406), v. 26, n. 6, p. 813-840, 2005.

YAN, T.; DOOLEY, K. J. Communication intensity, goal congruence, and uncertainty in buyer-supplier new product development. Journal of Operations Management, v. 31, n. 7, p. 523-542, 2013.

ZAHEER, A.; MCEVILY, B.; PERRONE, V. Does Trust Matter? Exploring the Effects of Interorganizational and Interpersonal Trust on Performance. Organization Science, v. 9, n. 2, p. 141-159, 1998. 